\title{
Safety Research on Filling Collapse by Dumping Rocks along the Collapse
}

\author{
Yan Wang ${ }^{1,2}$ and Weibo Sun ${ }^{1,2}$ \\ 1. Key Laboratory of Western Mine Exploitation and Hazard Prevention, Ministry of Education, Xi'an 710054, China \\ 2. School of Energy Engineering, Xi'an University of Science and Technology, Xi'an 710054, China
}

\begin{abstract}
Because the large collapse pits appeared in the surface of stoped-out area in the lower iron belt of the southeast of Gongchangling iron mine, the sliding danger of side wall of collapse pit threats seriously the production safety of open-pit of upper iron belt. The harm forms of collapse pit, especially the subsided harm of the bottom of granular media are analyzed. The experiment shows the possibility of the granular media forming the arch in the course of mining and analyzes the continuity of bulk movement. Then it can be concluded that the granular media of pit bottom will not suddenly subside in the process of downward shift. Therefore, a technical scheme of drawing the open-pit stripping rock along the collapse pit was proposed and the rock can be dumped along the collapse pit trend and wall safely.
\end{abstract}

Key words: Collapse, fill, dispersion.

\section{Introduction}

In the underground mining of metallic deposit, goaf caused failure of surrounding rock, surface collapse pit, and the peripheral cracks, formation of subsided area [1]. The southeast of Gongchangling iron mine has two parallel ore belts, which are 40-200 m apart, and the lower iron belt is magnetite iron conducted to the underground mining and the upper iron belt is Hematite lagging behind the open pit mining, which caused a $300 \mathrm{~m}$ dispersion between upper and lower iron surface [2]. Besides that, when The goaf is caving through the surface, a collapse pit, with the size of 30-100 m width and 20-55 m height formed near the open pit. Because the wall of collapse pit is close to vertical, the production safety is threatened by the rock movement of the open-pit. For the protection of the collapse pit wall and improving the rock breaking efficiency, authors put forward the technological scheme of discharging strip waste to the collapse pit. The plan needs to discharge waste rock alone the collapse pit direction with the coordination of side wall, namely the

Corresponding author: Weibo Sun, Ph.D., main research fields: mining methods, blasting technique. waste rock should be filled above the dispersion in the collapse pit. Therefore, it needs to analyze the harm form of collapse pits, evaluate the reliability of this method to guarantee production of the waste rock safely.

\section{Analysis of Harmfulness of Collapse Pit}

Because the collapse pit is located on the hillside, both sides of the rock are not in the same height, the dump height to along the strike is above the uphill height but below downhill. On this condition, the main hazard of collapse pit is uphill side cliffs fall hazards and collapse pit collapse hazard. By analyzing the fall occurring conditions of surrounding rock slice, mainly no lateral support force, if there is a lateral support force, fallen degree will be limited; if there is enough large supporting force, it will have no lateral leaves. Falling dispersion in goaf gradually comes to compact, playing a key role to fallen wall. Collapse pit side wall to maintain stability, need to dispersion maintain liquidity better in down process, and side wall supporting role to have big enough. The supporting role of dispersion on the side wall can be attributed to the granular particles lateral pressure on side wall. 
Pressure can be reflected by the lateral pressure coefficient. The lateral pressure coefficient is a close contact with the natural repose angle, granular size and inter particle friction and adhesion [3].

The dispersion of continuous treatment, in the limit equilibrium state, dispersion of active stress state can be expressed as [4]:

$$
\begin{gathered}
\sigma_{z}=\gamma z \\
\sigma_{x}=\gamma z \frac{1 \mp \sin \varphi}{1 \pm \sin \varphi}
\end{gathered}
$$

In the southeast region containing iron footwall cover layer dispersion conditions, under the influence of underground mining down process, the side pressure should be smaller than the static lateral stress, and the angle of internal friction approaching the natural repose angle. From the field of drawpoint and open-air waste rock field measured, loose state, natural repose angle of dispersion is about 38 degrees. Gongchangling iron mine collapse pit loose cohesionless, internal friction angle is about 38 degrees. At this time, the maximum value of the passive compression stress is about 17.5 times as active compressive stress, passive pressure stress coefficient:

$$
\eta_{1}=\frac{1+\sin \varphi}{1-\sin \varphi}=\frac{1+\sin 38^{\circ}}{1-\sin 38^{\circ}}=4.20
$$

Gongchangling iron ore rock broken expand coefficient is 1.50 , because $4.20 / 1.50=2.80>1$, so the maximum passive pressure of falling dispersion is greater than the maximum principal stress with thickness solid rock gravity stress. Accordingly, the passive pressure collapse pit dispersion stress, should be the main force to stop the side wall rock broken, thereby limiting of surrounding rock of the side wall of fallen.

Based on the supporting effect of dispersion on collapse pit side wall, in the row of rocks along the strike at the same time, a collaborative dumping rock measurement should be adopted from the uphill side, which makes the height of rocks along the strike row higher than the uphill side rock rolled to the bottom 3-5 m. Using the waste stone to cover the rock, and the impact is not on the top along the strike of waste rock field, which can completely prevent the slope rock fall hazard. On this condition, subsiding of dispersion in collapse pit has become the only main form of damage.

Granular media in the bottom of collapse pit moved with ore body, according to the research of stochastic medium theory of ore drawing [5], the relationship between maximum velocity $v_{z}$ and height level of granular media change $h$ is:

$$
v_{z} \approx \frac{q}{\pi \beta h^{\alpha}}
$$

where $\alpha, \beta=$ granular flow parameters, $\mathrm{h}=$ level; $\mathrm{q}=$ The volume of discharged of granula media in unit time in lower mining stope.

The average height of Gongchangling collapse pit of granular layer is about $300 \mathrm{~m}$. The bottom ore body uses sublevel caving method and short-hole shrinkage method, the former method uses a bucket capacity 2.0 $\mathrm{m}^{3}$ scraper, a discharge capacity of about $2.0 \mathrm{~m}^{3}$. because the latter method caving pillar stope downward at the top brings the maximum dispersion and according to estimates of volume of room and pillar, after top pillar caving, granular media will move about $10 \mathrm{~m}$, equivalent to the released amount not exceeding $28.2 \mathrm{~m}^{3}$. Substituting the granules flow parameters by experimentally measured $\alpha=1.1937, \beta$ $=0.3959$ and $\mathrm{q}=28.2 \mathrm{~m}^{3}, \mathrm{~h}=300 \mathrm{~m}$ into Eq. (1) to calculate the collapse pit surface dispersion, one of the biggest down value is about $0.025 \mathrm{~m}$, this downward capacity is not enough to endanger the safety of the waste rock filling. That is to say, if the granular media is a continuous flow, no collapse hazard will happen. Analysis shows that, the only happening condition of subsidence hazard, is a massive arching forming during flow process for the granular media in the collapse pit. Once the arch forms, a sudden arch collapsing may 
cause a sudden subsidence. Therefore, whether the arch forming for granular media in the collapse pit or not, decides whether the rock discharging operation personnel and equipment will be collapsed.

\section{Granular Arch Experiment}

The flow of granular arching mainly depends on the collapse zone width and dispersion flow characteristics. Gongchangling mine collapse pit width is $10-50 \mathrm{~m}$. Under this condition, to find out the main factors affecting the flow characteristics of dispersion is one of experimental studies. The main influence factors listed as Literature are moisture content, clay content and block [6-9].

The Gongchangling mining area is mainly the Archean Anshan group CI Gou group. The hydrogeological conditions are simple and water abundance of rock is very weak [10]. In the granular, powder ore and clay content are very low, the main factors affecting the flow characteristic of the granular are block composed.

Practice shows that, on the surface of loose rock heap on the levels of area, percentage of rock block, and pile body at all levels of the percentage of the volume of rock block is almost the same. Therefore, through the method of photographing sampling measurement to measure the loose rock fragmentation. Commonly used methods: directly in the loose rock heap on the surface area of a certain size, measurement circle, with the grid to the determination of rock block of loose rock ratio.

By the end of the stope ore funnel statistics block degree of rock exposed (Table 1), combined with the ground surface dispersion of block degree dew out pit collapse, taking into account the two crushing effect dispersions in down process. The estimated collapse pit internal dispersion of rock fragmentation components are shown in Table 1.

The visible part of the granular piles covering layer, in addition to underground stope chute, and the bottom surface of the collapse are on the exposed surface. According to the measurement results, the upper surface of rock fragments (block size is less than $5 \mathrm{~cm}$ ) and soil accounted for about $25 \%$, particle size chunks of rock more than $100 \mathrm{~cm}$ accounted for about $5 \%$, most of the rest $70 \%$ dispersion of rock block is smaller than $30 \mathrm{~cm}$.

Taking into account the two crushing effect dispersions in down in the process of covering layer dispersion, internal average block size should not be less than the waste rock in the ore can be seen at the mouth of the average block size. Therefore, on the basis of the drawpoint visible rock fragmentation and surface collapse pit saw the rock fragmentation, estimation of covering granular piles of rock fragmentation. The estimation results in Table 2.

Table 1 The funnel mouth exposed rock fragmentation statistics.

\begin{tabular}{lll}
\hline Number & Rock fragmentation $(\mathrm{cm})$ & $\%$ \\
\hline 1 & $\mathrm{D} \leq 5$ & 19.6 \\
2 & $5<\mathrm{d} \leq 30$ & 53.4 \\
3 & $30<\mathrm{d} \leq 100$ & 21.3 \\
4 & $100<\mathrm{d}$ & 5.7 \\
Total & & 100 \\
\hline
\end{tabular}

Table 2 Covering layer dispersion of rock fragmentation.

\begin{tabular}{lll}
\hline Number & Rock fragmentation $(\mathrm{cm})$ & $\%$ \\
\hline 1 & $\mathrm{D} \leq 5$ & $20-25$ \\
2 & $5<\mathrm{d} \leq 30$ & $50-60$ \\
3 & $30<\mathrm{d} \leq 100$ & $10-24$ \\
4 & $100<\mathrm{d}$ & $5-6$ \\
Total & & 100 \\
\hline
\end{tabular}


According to the measured data, taking a part of the underground mining stope as the model length and the distance between collapse pit and draw hole as the model weigh, the model is designed by $1: 100$. The length of model is $25 \mathrm{~cm}$ and height is $70 \mathrm{~cm}$, and width can be changed, draw hole size is $3 \mathrm{~cm} \times 3 \mathrm{~cm}$. Considering the friction between granular flow with collapse pit wall, a 100 sandpaper was in the model of ore port on the side wall with, close to the side of draw hole side wall has not posted sandpaper, shape arch the flow state can be observed from the side of the internal node dispersion and positive face.

The experimental dispersion by the ore by crushing screening, granular fragmentation and graded are shown in Table 3.

The experiment is based on the theory of similarity to search the relationship between particle size in natural state and gradation and flow continuity. The experiment is divided into two groups, the first group the same size experiment, to explore in the size condition dispersion arching rules; second groups of similar experiments, explore the natural state collapsed arch rules pit dispersion.

Size experiment is under the walls and a plurality of draw hole ore under the influence, by adjusting the width of the side wall of different span ratio, simulate the collapse pit dispersion in multi draw hole out dispersion in mining process flow and arching condition.
Model $1 \mathrm{~cm}, 1.25 \mathrm{~cm}, 1.5 \mathrm{~cm}$ in width, $1.75 \mathrm{~cm}$, the experimental results are shown in Table 4.

Therefore, when the span ratio of $\mathrm{R}>3$, won't appear arching phenomenon, when the span ratio of $\mathrm{R}$ $<2$ will appear when the massive arching phenomenon, span is more than $2 \leq \mathrm{R} \leq 3$, arch and smaller.

Similar experiments the experimental conditions of equal size experiment, model $1.25 \mathrm{~cm}, 1.5 \mathrm{~cm}$, width of $1.75 \mathrm{~cm}, 2 \mathrm{~cm}, 2.25 \mathrm{~cm}, 2.5 \mathrm{~cm}, 2.75 \mathrm{~cm}, 3 \mathrm{~cm}$ and $3.25 \mathrm{~cm}$. Select the average particle dispersion accounted for $10 \%$ of total weight of the larger particles size group size as a symbol of mixed dispersion particle size. Dispersion used in this experiment, weight $10 \%$ larger particle size, particle size of particles greater than $13.2 \mathrm{~mm}$ accounted for about 5.5\%, 10-13.2 mm particles accounted for about $4.5 \%$, by calculation, the mixed dispersion symbol size is $12.48 \mathrm{~mm}$. The experimental results as shown in Table 5 .

At this time when the span ratio $\mathrm{R} \geq 2.6$, particles can be continuous flow, do not appear to have stalled, block, arching phenomenon; when the span ratio of $\mathrm{R}<$ 1.6 when block, arching phenomenon; when the span is $1.6 \leq \mathrm{R}<2.6$ and between, the occasional pauses, flow block and a small arch phenomenon.

Similar experiments with particle size comparison, whether dispersion can span slow continuous flow ratio or began to span a certain scale arching phenomenon

Table 3 The contrast of the dispersion on site and the dispersion in test.

\begin{tabular}{llll}
\hline & Scene & & Experiment \\
\hline Rock fragmentation & Percentage & Rock fragmentation & Percentage \\
\hline$>100 \mathrm{~cm}$ & $5 \%-6 \%$ & $>13.2 \mathrm{~mm}$ & $5.5 \%$ \\
$30 \mathrm{~cm}-100 \mathrm{~cm}$ & $10 \%-24 \%$ & $5 \mathrm{~mm}-13.2 \mathrm{~mm}$ & $17 \%$ \\
$5 \mathrm{~cm}-30 \mathrm{~cm}$ & $50 \%-60 \%$ & $0.65 \mathrm{~mm}-5 \mathrm{~mm}$ & $55 \%$ \\
$<5 \mathrm{~cm}$ & $20 \%-25 \%$ & $<0.65 \mathrm{~mm}$ & $22.5 \%$ \\
\hline
\end{tabular}

Table 4 The results of equal diameter experiments.

\begin{tabular}{llll}
\hline $\begin{array}{l}\text { Model width } \\
\mathrm{S}(\mathrm{cm})\end{array}$ & $\begin{array}{l}\text { Particle size } \\
\mathrm{D}(\mathrm{mm})\end{array}$ & $\begin{array}{l}\text { Span ratio } \\
(\mathrm{R}=\mathrm{S} / \mathrm{D})\end{array}$ & $\begin{array}{l}\text { Arch times } \\
(3 \text { time) }\end{array}$ \\
\hline 1 & $5.0<\mathrm{d}<6.0$ & $1.67-2$ & 3 (Large) scale) \\
1.25 & $5.0<\mathrm{d}<6.0$ & $2.07-2.5$ & 3 (Small scale) \\
1.5 & $5.0<\mathrm{d}<6.0$ & $2.5-3$ & 1 (Smaller scale) \\
1.75 & $5.0<\mathrm{d}<6.0$ & $3-3.5$ & 0 \\
\hline
\end{tabular}


Table 5 The results of similar experiments.

\begin{tabular}{llll}
\hline $\begin{array}{l}\text { Model width } \\
\mathrm{S}(\mathrm{cm})\end{array}$ & Particle size & Span ratio & Granular flow \\
\hline 3.25 & $\mathrm{D}(\mathrm{mm})$ & $\mathrm{R}$ & Good fluidity \\
3 & 12.48 & 2.60 & A block \\
2.75 & 12.48 & 2.4 & A block and a small arch \\
2.5 & 12.48 & 2.2 & The flow is not smooth, a block \\
2.25 & 12.48 & 2 & A block and a small arch \\
2 & 12.48 & 1.8 & Many block \\
1.75 & 12.48 & 1.6 & Small scale arch \\
1.5 & 12.48 & 1.4 & Large scale arch \\
1.25 & 12.48 & 1.2 & Large scale arch \\
\hline
\end{tabular}

than, similar experiments were smaller than the size of experimental. Visible, in the presence of smaller particles, liquid dispersion will be better.

Also found in the experiment, the granular arch cavity, from the cavity side continue to emit the dispersion, particle dispersion cavity surrounding and lower will continue to move downward, and the cavity at the top of the particles, often accompanied by side bulk down and lateral movement. Lateral move the top particles are destructive to the arch structure, often make the arch collapse. In addition, the arch side release dispersion, often drive the arch edge of granular flow, the arch gradually narrowed or collapse.

The particle size of experiment and similar experiments, the granular flow by two boundary constraints, have arch span ratio $\mathrm{R} \leq 1.6$.

\section{Along the Collapse Pit Waste Rock Safety Reliability Analysis}

According to the experimental results, marks dispersion size in Gongchangling mine collapse pit covering layer is less than $1.0 \mathrm{~m}$. Considering the safety factor is 1.5 , granular arch span is not more than $2.4 \mathrm{~m}$. The actual width of recovery of the orebody is $10 \sim 55 \mathrm{~m}$, which is 4.4-22 times of the arch span, therefore, the possibility of large-scale arch forming during the process of dispersion in collapse pits moving down is very small.

At the same time, because of the far distance of collapse pit to stope and the effect of dispersion and absorbing wave of covering layer on the collapse pit, the effect on the collapse pit side wall stability by explosive vibration is very small, therefore, the underground mining blasting does not cause a sudden collapse of the pit side wall buckling down. So, the implementation of security can measure the technology above the rock collapse pit row.

Authors use the collapse pit and wall rock to coordinate scheduling scheme, near the stope along the direction of emission of waste rock pit side collapse, collapse pit in the hanging side along the wall of stope collapse pit waste emission efficiency, waste rock for such higher. In addition, the pit wall collapse on the footwall is affected by the effects of dispersion on dispersion slope by extrusion, extrusion to discharge filling dispersion makes the rock more secure, control side wall piece effect more obvious. The scheme is shown in Fig. 1.

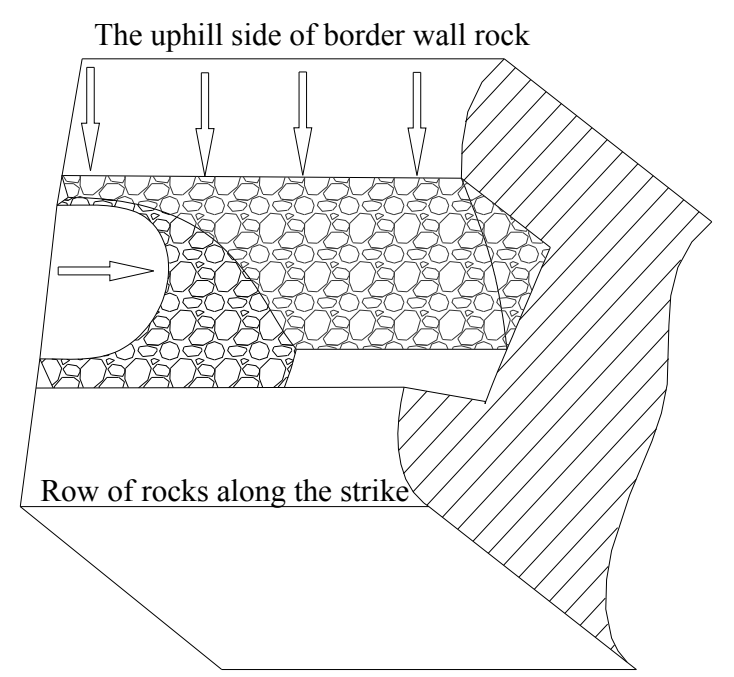

Fig. 1 The rock discharging scheme. 


\section{Conclusion}

For Gongchangling iron southeast area collapse pit opencast stope safety hazards, the best approach is to use waste rock filling collapse pit strip.

Experiment, bow mine collapse pit dispersion will not be a large-scale arching phenomenon, which doesn't happen collapse hazard, therefore has the condition to realize the construction safety collapse pit discharge waste rock.

The production practice shows that, by adopting the technical scheme of the collapse pit wall rock discharging direction and coordination are safe and reliable, not only can effectively prevent the pit wall fall (or fall) activities to ensure the safety in production of ore containing iron bow east open pit, but also greatly reduces the waste rock from the transport, improving the rock breaking efficiency.

\section{References}

[1] Xie, S. J. 2008. Underground Mining of Metallic Deposit. Bei Jing: Metallurgical Industry Press, 2008.

[2] Li, H. Y., Ren, F. Y., Chen, X. Y., and Gong, G. H. 2012.
"The Method for Predicting and Controlling the Range of Surface Subsidence during Deep Ore-Body Mining." Journal of Northeastern University (Natural Science) 11: 1624-27.

[3] Wang. C. H. 1982. Ore Drawing Science, Beijing: Metallur-gical Industry Press.

[4] Harr. M. E. 1977. "Mechanics of Particulate Media." New York: The McGraw-Hill Incorporation, 268-74.

[5] Ren. F. Y.1994. Drawing Theory in Random Med-um and its Application, Beijing: Metallurgical Industry Press.

[6] Tao, G. Q., Yang. S. J., and Ren. F. Y. 2009. "Experimental Research on Granular Flow Characters of Caved Ore and Rock." Rock and Soil Mechanics 10: 2950-4.

[7] Wang, H. J., Yin, S. H., Wu, A. X., and Shen, H. M. 2010. "Experimental Study of the Factors Affecting the Ore Flow Mechanism during Block Caving." Journal of China University of Mining and Technology 5: 693-8.

[8] Wu. Y., Zhu, A. X., Xi, Z. G. and Zhang, X. S. 2006. "Study on Flowing Law of Caved Ore-Rock Bulk." Metal Mine 4-6.

[9] Zhang. C. Y. 2009. Simulation of Movement of Loose Ore and Rock Flow of High Viscosity, Changsha: Central South University.

[10] Lu. H. et al. 2008. Liaoning Province Liaoyang City Gongchangling Iron Ore Resources Exploration Report. Anshan: Bureau of Geological Exploration Institute of Liaoning Province Metallurgical Geological Prospecting. 